\section{Surgical Treatment of the Older Age Children with Congenital Recurrent Clubfoot Using Method of Transosseous Osteosynthesis by Ilizarov}

\author{
Leonchuk SS, Neretin AS and \\ Ivanov GP \\ Russian Ilizarov scientific center for \\ Restorative traumatology and orthopaedics. \\ 6, M. Ulianova str., 640014, Kurgan, Russia
}

Corresponding author: Sergey S Leonchuk

” leon4yk@mail.ru

Purpose of the study: In this study assessment of treatment results of old age children (13-18 years) with congenital recurrent clubfoot at the RISC'RTO' by the method of transosseous osteosynthesis was done.

Materials and methods: In our clinic from 2004 to 201665 children (77 feet) aged 13-18 (mean age was 14.6 years) with congenital recurrent clubfoot have been treated. All patients were treated by llizarov method. In this group of patients together with insertion of wires in the tibia and foot, appropriate llizarov frame assembly we used surgical interventions on soft tissues, osteotomies and stabilizing surgeries.

Results: Long-term results (average 40 months follow-up) noted in 55 (84.6\%) of patients by AOFAS (American Orthopedic Foot and Ankle Society) scale: In $67.3 \%$ of cases (37 patients) noted good treatment results, poor outcomes ( $26.3 \pm 10.0$ points according to AOFAS)-in 4 cases (7.3\%).

Conclusion: Application of the method of transosseous osteosynthesis by llizarov in management of children with congenital recurrent clubfoot allows us to achieve desired results and to reduce possibility of recurrent development of the segment deformity.

Keywords: Clubfoot; Recurrence; Transosseous osteosynthesis; Older age children; Ilizarov; External fixator
Sergey S. Leonchuk, MD, head of the 6th orthopaedic department, Kurgan, Russia.

Citation: Leonchuk SS, Neretin AS, Ivanov GP. Surgical Treatment of the Older Age Children with Congenital Recurrent Clubfoot Using Method of Transosseous Osteosynthesis by llizarov. J Bone Rep Recomm. 2017, 3:1:1-7.

\section{Introduction}

Congenital clubfoot is a malformation of the osseous, muscular and vascular systems associated with impaired activity central and peripheral nervous system as a result of total body dysplasia with mainly affecting the foot and tibia [1]. Annually over 100 thousand children are born in the world with this type of disease [2], which tends to recurrence within the growth process of a child $[3,4]$. In spite of quite sufficient study of this problem questions of etiopathogenesis didn't find a single response. Patients of the age group ranged from 13 to 18 , as a rule, have time to receive medical treatment (most of them many times) using various techniques: staged plaster bandage, different variants of tenoligamentocapsulotomies, stabilizing surgeries, instrumental correction [5-15]. However, according to several authors' recurrence of the clubfoot ranged from $15-50 \%$, which is associated not only with the disease itself but with a tendency to recur in the growth process of a child but with presence of rough postoperative scars delaying foot development. Therefore, surgical treatment of this group of patients is very difficult until now.

Techniques of transosseous osteosynthesis based on biological laws opened by academician Ilizarov are connected with dosed elimination of components of the foot deformity by means of gradual extension of shortened soft tissues, tendonligamentous apparatus of the foot and ability of the bone tissue to transformation $[16,17]$. Possibility to use various Ilizarov frame assemblies in sparing optimal rigidity of fixation of the foot bones with their dosed translation in necessary direction allows us to correct any foot deformity and/or its parts $[4,11,13,14]$. 
So, this study was done to evaluate results of surgical treatment of multicomponent recurrent foot deformity which can help orthopedic surgeons to solve this problem and to assist in reduction of recurrence rates.

\section{Materials and Methods}

In our clinic from October, 2004 to March, 201665 children (77 feet) aged 13-18 with congenital recurrent clubfoot (mean age was 14,6 years) have been treated. Minimum follow-up after surgery was 10 months (average 40 months, ranged from 10 to 72 months). To assess the condition of the patients, the choice of the most appropriate method of treatment, the course of reparative processes and analysis of treatment results, we used the clinical and $X$-ray examination. Before treatment clinical evaluation of the ankle joint and the foot was done to examine people according to functional AOFAS scale [18]. Typical complaints to the deformity, pains in the foot wile loading, limitation of motions in the ankle joint, violation of the support ability of the lower limb, fast fatigue and inability of long time walking, difficulty in choice of the shoes also and cosmetic defect of the segment because of its shortening and also presence of rough scars of the shin and foot skin. In observation of the patient's tulips equinocavovarus adducts with prevailing of one or several components of the deformity were noted. In 44 children (67.8\%) dominating of such a deformity components as equines and adduction were noted. It was associated with presence of scars from $8-20 \mathrm{~cm}$ on the posterior surface of the lower third of the tibia and medial plantar foot surface, soldered with subjacent tissues. In this group of patients were clinically noted joint contractures of operated foot. 9 patients (13.8\%) had previous scars, but they were mobile. 12 patients (18.4\%) have been treated before with conservative methods (plaster bandaging). In evaluation of patients function, pain syndrome and ability of hind-and middle foot to adaptation on the flat surface, total points according to AOFAS scale before our treatment varied until 36 points. We used X-ray examination to define degree of impaired anatomical correlations of bony structures of the tibia and the foot. On admitting to the stationary was done radiography of the foot with ankle joint in AP and $M L$ views and also forefoot in AP view (plantar) with load.

We developed our scheme of surgical interventions in the older school age children considering clinical forms of the disease (Figure 1, classification of clubfoot by Diméglio [19]) and aged peculiarities of radiological anatomy of the foot bones [20]. We divided this group of patients into two subgroups depending on the existing level of foot shortening. All patients received wires in the tibia and the foot with corresponding assembly of the llizarov frame with hinge joints and an option of surgery on soft tissues and foot bones. In a pronounced norm and hypertrophic scars we used to do transverse incisions onto cicatricle tissues of the foot and or in cases of rough scars soldered with subjacent tissuestheir maximum excision.

Treatment of children aged 13-18 with foot deformity with its shortening less than $2.0 \mathrm{~cm}$. Foot deformity of the II degree by

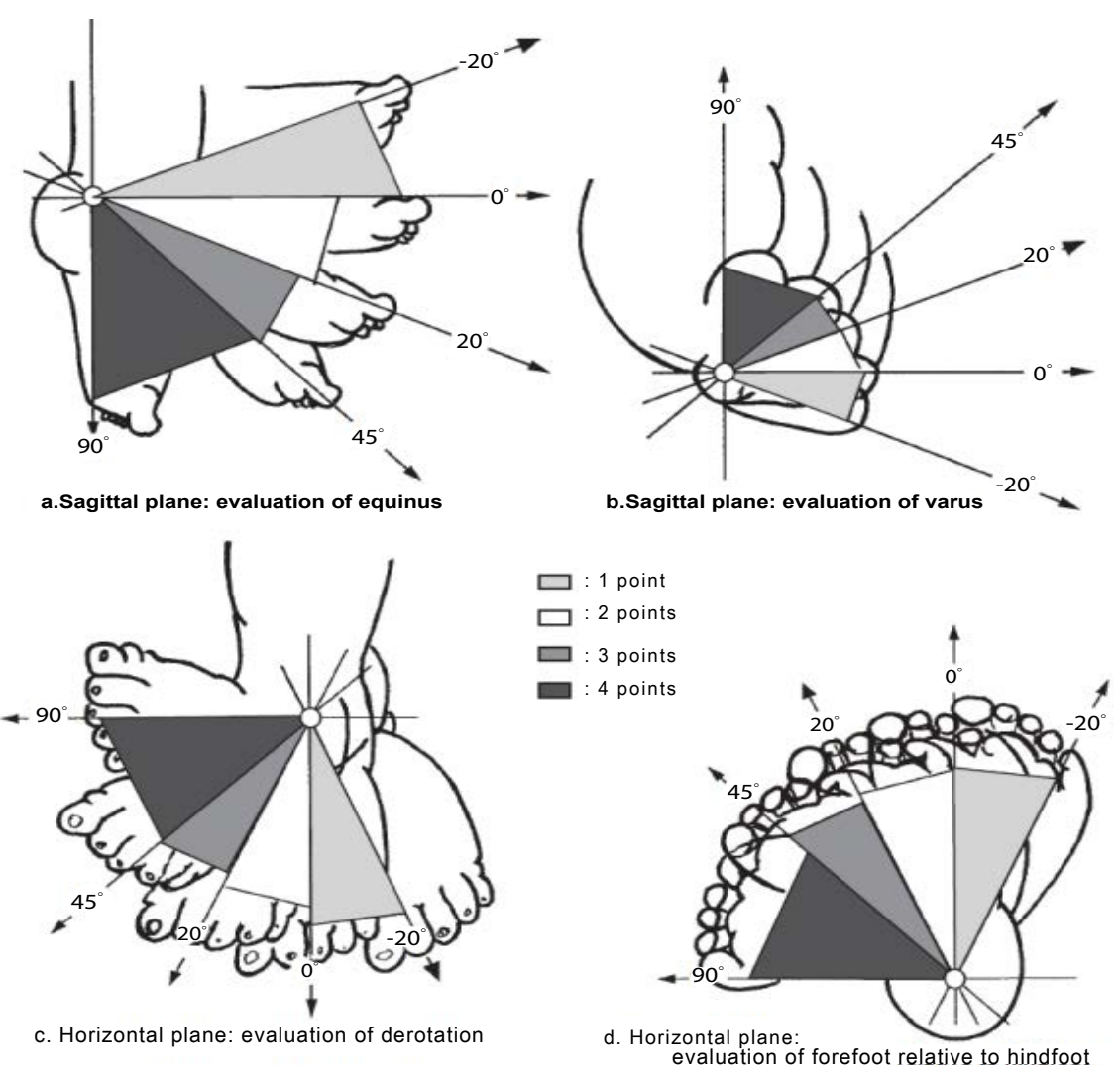

Figure 1 Diagrams of the evaluation of congenital talipes equinovarus used by Diméglio et al. [19]. 
Dimeglio (5-10 points) noted in 18 patients ( 24 feet) was corrected intraoperative using Ilizarov frame by means of correcting triple (talo-navicular, calcaneo-cuboid, talo-calcaneal) arthrodesis of the foot (Figure $\mathbf{2 a - 2 c}$ ) with preliminary intervention on soft tissues of the segment or dozed one using llizarov frame by means of osteotomy of the midfoot bones (cuneiform and cuboid bones) and calcaneus (Figure 3a-3c), if foot was rigid after surgical procedures on soft tissues ( 8 patients (10 feet)). Surgical intervention on soft tissues included percutaneous z-shaped achillotomy, tenotomy of flexors muscle of toes, capsulotomy of the metatarsophalangeal joints and plantotomy. In cases when osteotomy of the foot bones was done deformity correction by Ilizarov frame started on the 4-5 day.

Foot deformity of the III-IV degree by Dimeglio (10-20 points) noted in 17 patients (23 feet) was done dozed correction using Ilizarov frame starting from the 6-7 day after surgery with preliminary surgical intervention on soft tissues by percutaneous z-achillotomy, tenotomy of flexors muscle of toes, capsulotomy of the metatarsophalangeal joints and plantotomy. To prevent flexion contractures of the toes they were fixed with wires. Then, after gradual correction of foot deformity by llizarov frame triple arthrodesis was done as a stabilizing surgery (Figures 2 and 4).

In case of pronounced muscular imbalance was done transfer of the tibia muscle tendons to the edge of the feet by the classic method.

Treatment of children aged 13-18 with combination of the foot deformity and its shortening. Shortening over $2.5 \mathrm{~cm}$ and more was an indication for lengthening. In shortening of the foot and presence of the deformity of the II degree (16 children (16 feet)) was done gradual correction and segment lengthening using Ilizarov frame by osteotomy of the midfoot (cuneiform and cuboid bones) and calcaneus (distraction osteogenesis by llizarov (Figures 3 and 5). Correction started on the 4-5 day after surgery. In cases of the III-IV degree of the foot deformity (14 patients (14 feet) with existing shortening of the segment after gradual deformity correction by llizarov frame was done triple arthrodesis

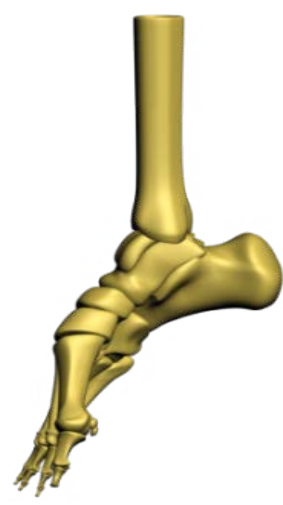

a

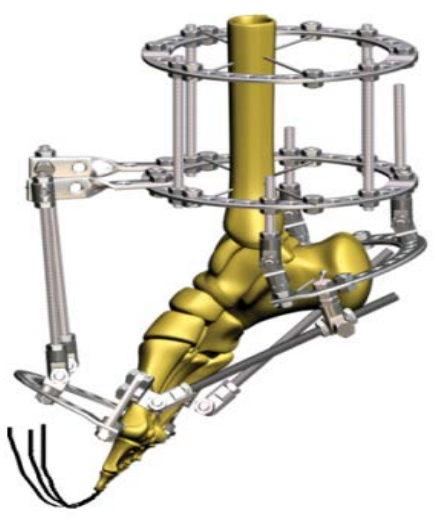

b

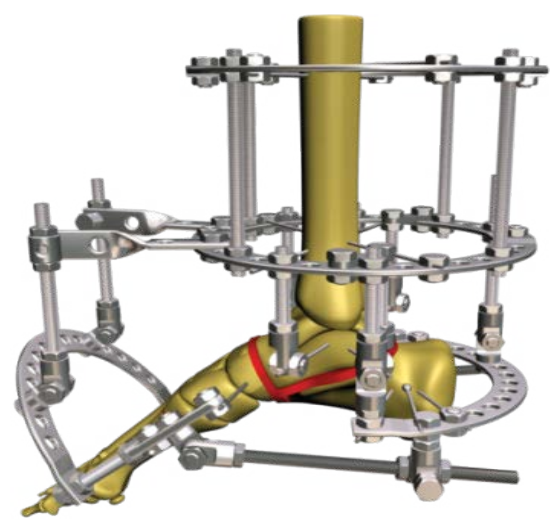

$\mathrm{C}$

Figure 2 (a) Diagram of the foot bones in congenital clubfoot; (b) Diagram of wire insertion on a tibia and a foot, assembly of the llizarov frame; and (c) Performance of triple arthrodesis of the foot in llizarov frame.

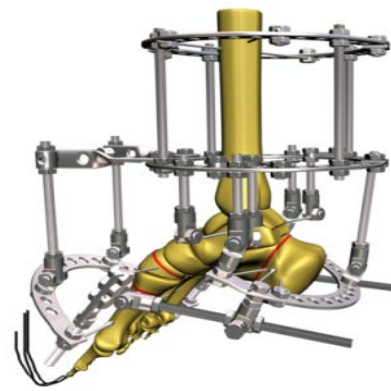

a

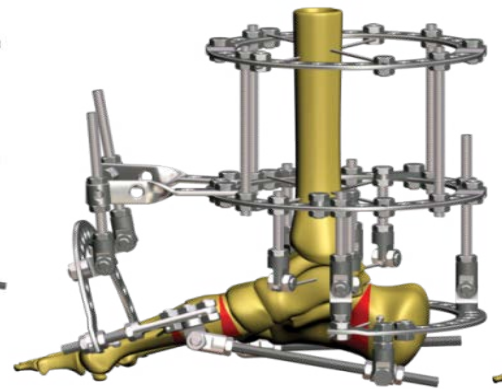

b

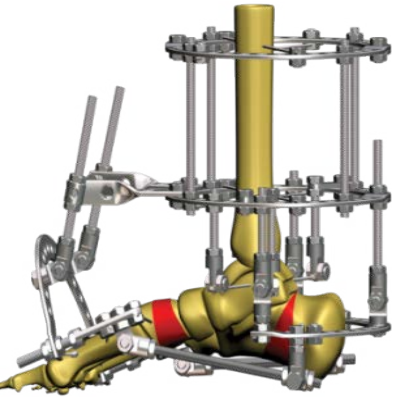

C

Figure 3 (a) Diagram of osteotomy of the midfoot and calcaneal bone, insertion of wires on a tibia and a foot, assembly of the llizarov frame; (b) Diagram of contact regenerate formation at the osteotomy zones during correction in the llizarov frame; and (c) Diagram of the distraction regenerate formation in foot lengthening by the llizarov frame. 


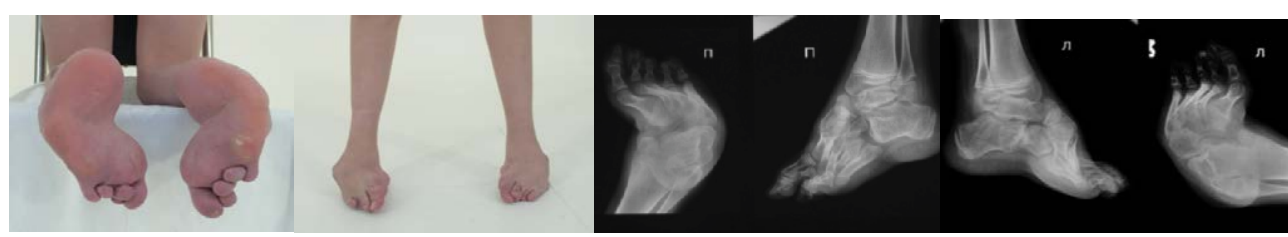

a

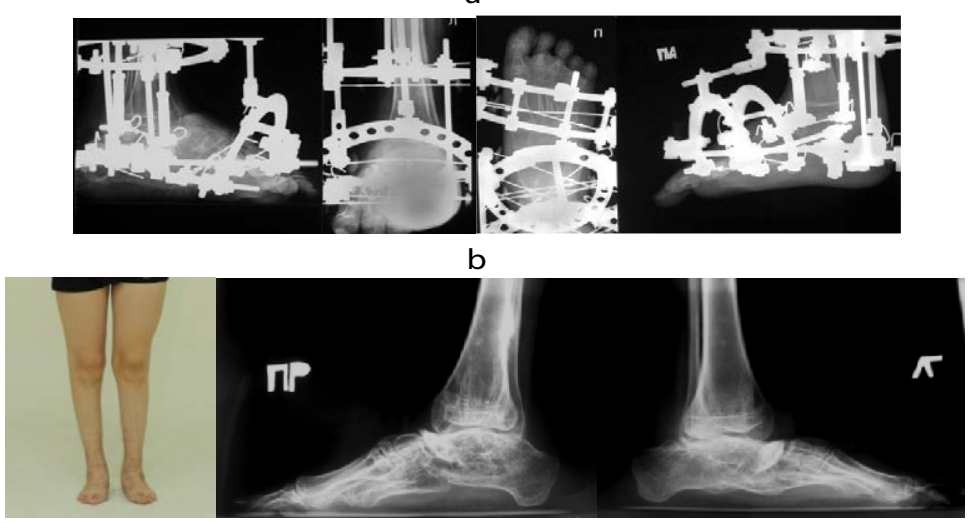

Figure 4 (a) Before treatment; (b) During the treatment by llizarov frame; and (c) 2 years after treatment.

of the foot at first stage (Figure 2a-2c). Foot lengthening was done in the second stage of treatment according to described earlier our methods (distraction osteogenesis) (Figure 3a-3c). In this group (patients with deformity and shortening of foot) tendon transfer was done in 3 cases after lengthening of foot.

Foot lengthening was done by formation of distraction regenerate in the midfoot area and calcaneus (Figure 3c).

The studies were approved by the institutional committee and were performed in accordance with the ethical standards laid down in the Declaration of Helsinki. All persons included into the study gave their informed consent and the study of human subjects followed the rules of clinical practice in the Russian Federation (RF Ministry of Health order \# 266).

\section{Results}

Results of comprehensive study allowed obtaining data which dynamics served as an objective criterion of effectiveness of the medical therapies. Gradual correction of foot deformity by llizarov frame allowed us to overextend existed scars-changed soft tissues and to correct all deformity components with moderate hypercorrection 10-15 degrees because of the existing partial elastic tissue retraction of the medial-plantar foot surface after frame removal. Duration of distraction and fixation depended mainly on the degree of the deformity and foot shortening. Data about duration of correction of foot deformity see in the Table 1. Subsequent fixation of the segment by llizarov frame in group of patients without lengthening of foot was $45.4 \pm 6.2$ days.

In patients with deformity and shortening of foot average amount of lengthening was $3.78 \pm 0.9 \mathrm{~cm}$, duration of fixation by the frame-75.3 \pm 7.4 days.

Postoperative complications were observed in 14 patients which was $21.5 \%$ of the total number of treated patients of this group.
Among them inflammation of soft tissues around wires in 5 (7.7\%), cutting of soft tissues with wires in $3(4.6 \%)$, premature consolidation at the area of osteotomy in $2(3.1 \%)$, subluxation of the ankle joint in $2(3.1 \%)$ and cutting of wires out of the bone was noted in 2 (3.1\%) patients. All encountered complications have been eliminated during treatment process and didn't affect the final result of it.

Long-term results (average 40 months, ranged from 10 to 72 months) of our treatment were analyzed in 55 patients (84.6\%) by point-based system AOFAS (Table 2). Among long-term treatment results were distributed the following way: Good in 37 patient (67.3\%), satisfactory in 14 (25.4\%), poor -4 (7.3\%).

In all cases after conducted treatment was noted improvement of the functional condition of the foot and its cosmetic view versus preoperative.

\section{Discussion}

Traditional methods of conservative treatment of recurrent clubfoot in the group of old age children are ineffective [3-6]. In the front plan comes release of the hind- and medial-plantar areas of the foot or surgeries on the foot- and tibia bones with external fixator [8-11]. However, extended surgeries on soft tissues of the segment often lead to foot rigidity and formation of rough painful postoperative scars $[13,15,17]$. So, according to Lee et al. data more than a third of cases (35\%) [21-24]. After surgical treatment of the foot deformity required in the future osteotomy of the foot bones. We consider that in correction of congenital recurrent clubfoot in older children against scarsoft tissue and anatomical abnormalities of the skeletal system transosseous osteosynthesis by llizarov is a method of choice.

According to the data of Sadofieva [20] to the beginning of this age period occurs ossification of the apophyges of tubular bones and 
Table 1: Foot deformity.

\begin{tabular}{|c|c|c|}
\hline $\begin{array}{c}\text { Degree of deformity } \\
\text { of a foot by Dimeglio }\end{array}$ & $\begin{array}{c}\text { Wuration of distraction (days) } \\
\text { Without lengthening } \\
\text { of foot }\end{array}$ & $\begin{array}{c}\text { With lengthening of } \\
\text { foot }\end{array}$ \\
\hline II & $27.6 \pm 3.1$ & $35.4 \pm 8.1$ \\
\hline III & $60.2 \pm 6.1$ & $78.1 \pm 13.3$ \\
\hline IV & $72.3 \pm 6.08$ & $88.2 \pm 12.52$ \\
\hline
\end{tabular}

Table 2: Clinical results by AOFAS.

\begin{tabular}{|c|c|c|c|c|c|c|}
\hline Preoperative & $\mathbf{n}$ & $\%$ & Last follow-up & $\mathbf{n}$ & $\%$ & P-value \\
\hline \multirow{2}{*}{$28.7 \pm 10.8$} & \multirow{2}{*}{65} & \multirow{2}{*}{100} & $81.5 \pm 8.1$ & 37 & 67.3 & $<0.001$ \\
\hline & & & $61.3 \pm 6.2$ & 14 & 25.4 & $<0.001$ \\
\hline & & $26.3 \pm 10.0$ & 4 & 7.3 & $<0.001$ \\
\hline
\end{tabular}

tarsal bones. Cartilaginous structure is saved in met epiphyseal growth plates of the tibia, short tubular bones of the foot and growth plates of apophyges. Based on these data we used selective approach for surgeries in patients of this group (osteotomy, arthrodesis, lengthening of foot). Gradual foot deformity correction by the llizarov frame allowed us to overextend existing scarring soft tissues and to correct all components of segment deformity with moderate hypercorrection 10-15 degrees to prevent recurrence development. In correction of the deformity using llizarov frame we corrected foot deformity by reduction of existing subluxations at the talonavicular and subtler joints and (or) translation of bone fragments after performed osteotomies (Figures 3 and 6). In usage of the llizarov frame in Bradish et al. [22] study poor results were noted in $11.8 \%$ of cases. In Ferreira et al. study [3] in terms of observation on average in 58 months after treatment poor results after segment deformity correction by llizarov frame were noted in $13.2 \%$ of cases and recurrence of the deformity was found in 19 feet (50\%). $12.1 \%$ of treated feet in Barbary study [5] had recurrence of some components of the clubfoot deformity after its correction using llizarov frame. In Ahmed paper unsatisfactory results were found in $27.8 \%$ cases [21].

But in this study have been observed partial recurrence of the treated foot deformity in $7.3 \%$ of cases. Cause of recurrent foot deformity in all cases was incompliance of patients with recommendations of orthopedic surgeon aimed at the preservation of obtained result.

It is important to note that all patients after correction of the rough segment deformity started walking with support on the plantar surface of the foot using special foot support made of rigid polyurethane foam trimmed with cloth for better adaptation of the foot to the support surface which was impossible in some techniques of the external frame correction [15].

Anyway, many colleagues told us about the good results of the usage of external fixator, where $72-84 \%$ of the cases were treated successfully $[3,4,21,24,25]$. In study of Grill and Franked [8] good treatment results were obtained in all cases. Any surgeons showed us that in some cases a period of work by external fixator was reached until 14 months $[6,25]$.

But today there is no common assessment scale and surgical scheme for the treatment of clubfoot and its recurrences in older age children.

Some authors noted sufficient number of complication in the usage of the transosseous osteosynthesis method such as soft tissue inflammation, pronounced edema, cutting of soft tissues with wires, subluxations in the phalanx of toes, premature consolidation at the area of osteotomy etc. [3-5]. Some of them were noted in our study. Together with it we consider that main preventive measures of complications are observation of base principles of the technique of transosseous osteosynthesis by
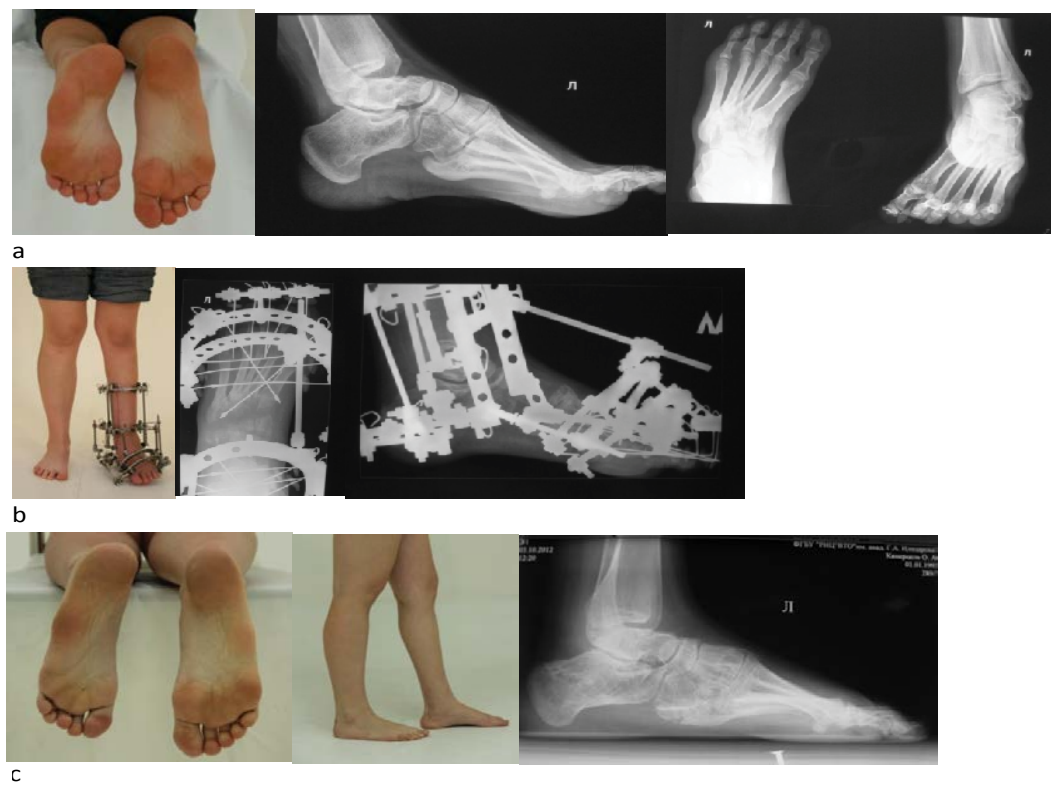

Figure 5 (a) Before treatment; (b) During the treatment; (c) After 2 year of our treatment. 


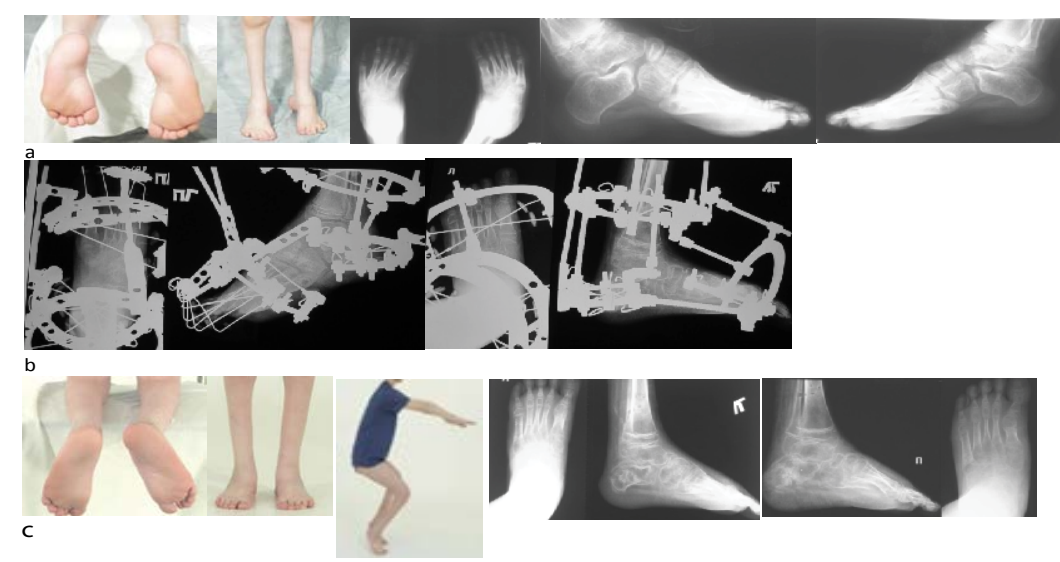

Figure 6 (a) Before treatment; (b) During of correction by llizarov frame; and (c) 1.5 year after treatment.

Ilizarov and rational observation of patients in the postoperative period $[8,11,13,15,22]$. For instance, prevention of soft tissue inflammation round wires was compliance with the rules of aseptic and antiseptic, regular and well performed dressing procedures. In the first 3-4 postoperative days changing of bandages was done every day by the doctor, then every week. To prevent cutting of soft tissues it is necessary to insert wires with corresponding skin reserve between supports to which traction forces are directed during deformity correction process and also observe necessary rate and frequency of distraction forces at preservation of necessary stable fixation of bones in a frame. Observation of the rate and frequency of distraction of the treatment process, timely and regular X-ray once in 7-10 days during correction allowed avoiding premature consolidation at the area of osteotomy. Correct placement of the rods connecting support of the interior part of a segment with a distal ring on the tibia was done to prevent subluxation in correction of the foot equines. Passing of wires through the calcaneal body in different planes allowed avoiding their cut out of the bone during correction.

After removal of the llizarov frame patient's limbs were immobilized with a plaster bandage from the upper part of the tibia up to foot toes in a position of hypercorrection of the foot up to $10-15^{\circ}$ in all deformity components for the period $1.5-2$ months. Patients are allowed to put the entire weight on the foot. After removal of the plaster bandage all the patients were recommended restorative treatment in the domiciliary clinic including wearing of an orthopedic shoe with an insole-pronator, limb immobilization with an Ankle-Foot Orthosis (AFO) for 6-12 months for the night, massage and redressing exercises for the foot and also physiotherapy aimed to improve trophic of the anterior-external group muscles of the tibia, foot and restoration of the range of motions in the ankle joint. Amplitude of motions in the ankle joint and joints of toes was restored up to initial one on the average in 4-6 weeks after the beginning of the active exercises. Lack of restorative treatment and refusal the rational shoe wearing and corrective insoles leads to developing of partial recurrence of the foot deformity which has been observed by us in 4 cases.

A limitation of our study is that we have not assessed the longterm effects of surgical treatment more than after 6 years. However, other authors have reported that favorable outcomes of such interventions persist until 107 month [3].

\section{Conclusion}

So, application of transosseous osteosynthesis method by Ilizarov in treatment of congenital recurrent clubfoot allows us to differentially perform surgical correction in children depending on the age peculiarities of the foot and degree of the deformity which is with combination of correct postoperative management and rational rehabilitation of patients contributes achieving of the good treatment result and minimizes possible deformity recurrence helping with social rehabilitation of a child.

\section{Conflict of Interest}

There are no conflicts of interest. 


\section{References}

1 Klychkova IY, Guseva IA, Yanakova OM, Barlova OV (2008) Clinical and physiological constituents of the congenital clubfoot. Travmatol Ortop Rossii 3: 35-38.

2 Ponseti I (2005) Clubfoot: Ponseti management ( $2^{\text {nd }}$ edn.). Global Help Publications p: 18.

3 Ferreira RC, Costo MT, Frizzo GG, Filho FF (2006) Correction of neglected clubfoot using the Ilizarov external fixator. Foot Ankle Int 27: $266-273$.

4 Shevtsov VI, Ismaylov GR (2008) Transosseous osteosynthesis in foot surgery. Meditsina Publishers p: 360.

5 Barbary HE, Ghani HA, Hegazy M (2004) Correction of relapsed or neglected clubfoot using a simple Ilizarov frame. Int Orthop 28: 183186

6 Mowafi HE (2004) Assessment of percutaneous V osteotomy of the calcaneus with Ilizarov application for correction of complex foot deformities. Acta Orthop Belg 70: 586-590.

7 Ettl V, Kirschner S, Krauspe R, Raab P (2009) Midterm results following revision surgery in clubfeet. Int Orthop 33: 515-520.

8 Grill F, Franke J (1987) The llizarov distractor for the correction of relapsed or neglected clubfoot. J Bone Jt Surg 4: 593-597.

9 Hofmann AA, Constine RM, McBride GG, Coleman SS (1984) Osteotomy of the first cuneiform as treatment of residual adduction of the fore part of the foot in club foot. J Bone Jt Surg 7: 985-990.

10 Hsu LP, Dias LS, Swaroop VT (2013) Long-term retrospective study of patients with idiopathic clubfoot with posterior medial-lateral release. J Bone Joint Surg Am 95: 271-278.

11 Kirienko A, Villa A (2004) Calhoun J.H. Ilizarov technique for complex foot and ankle deformities. Marcel Dekker Inc., p: 459.

12 Lejman T, Kowalczyk B (2002) Results of treatment of congenital clubfoot with modified Goldner's technique. Chir Narzadow Ruchu Orthop Pol 67: 351-354.
13 Paley D (1993) Correction of complex foot deformities using llizarov distraction osteotomies. Clin Orthop Relat Res 293: 97-111.

14 Schleicher I, Lappas K, Klein H, Szalay G, Kordelle J (2012) Followup of complete subtalar release for clubfoot-evolution of different scores. Foot Ankle Surg 18: 55-61.

15 Wayzi $\mathrm{H}$, Windhagen $\mathrm{H}$, Stukenborg-Colsman, Floerkemeier $\mathrm{T}$ (2011) Taylor spatial frame in severe foot deformities using double osteotomy: technical approach and primary results. Int Orthop 35: 1489-1495.

16 Ilizarov GA (1992) Transosseous osteosynthesis. Springer-Verlag, Heidelberg.

17 Ilizarov GA, Shevtsov VI, Kuzmin NV (1983) Method of treatment of the talipes equinocavus. Orthop Etraumat Prosthet 5: 46-48.

18 Kitaoka HB, Alexander IJ, Adelaar RS, Nunley JA, Myerson MS, et al. (1994) Clinical rating systems for the ankle-hindfoot, midfoot, hallux and lesser toes. Foot Ankle Int 15: 87-101

19 Diméglio A, Bensahel $H$, Souchet $P$, Mazeau $P$, Bonnet $F$ (1995) Classification of clubfoot. J Pediatr Orthop B 4: 129-136.

20 Sadofyeva VI (1990) Standard radioanatomy of the bone and joint system in children. Med Lening p: 220.

21 Ahmed AA (2010) The use of the llizarov method in management of relapsed club foot. Orthopedics 33: 881.

22 Bradish CF, Noor S (2000) The llizarov method in the management of relapsed clubfeet. J Bone Joint Surg 82: 387-391.

23 Lee DK, Benard M, Grumbine N, Pokrassa M, Weinstein S (2007) Forefoot adductus correction in clubfoot deformity with cuboidcuneiform osteotomy: a retrospective analysis. J Am Podiatr Med Assoc 97: 126-133.

24 Refai MA, Song SH, Song HR (2012) Does short-term application of an Ilizarov frame with transfixion pins correct relapsed clubfoot in children? Clin Orthop Relat Res 470: 1992-1999.

25 Makhdoom A, Qureshi PA, Jokhio MF, Siddiqui KA (2012) Resistant clubfoot deformities managed by llizarov distraction histogenesis. Indian J Orthop 46: 326-332. 